\title{
PERSONAL FORMALDEHYDE EXPOSURE LEVEL IN THE GROSS ANATOMY DISSECTING ROOM AT COLLEGE OF MEDICINE KING SAUD UNIVERSITY RIYADH
}

\author{
MUHAMMAD SAEED VOHRA \\ College of Medicine, King Saud University, Riyadh, Saudi Arabia \\ Stem Cell Unit, Department of Anatomy
}

\begin{abstract}
Introduction: This study was conducted to correlate the personal formaldehyde (FA) exposure levels of instructors and students with the indoor FA concentrations in gross anatomy laboratory at King Saud University. The personal FA levels of instructors and students are higher than the indoor FA concentration in the gross anatomy laboratory. Materials and Methods: The gross anatomy laboratory at college of medicine, King Saud University Riyadh, was observed for indoor FA concentration and the personal exposure levels of instructors and the medical students during the 4th, 10th and 14th weeks of the dissection sessions. All air samples were collected by the diffusive sampling device and analyzed by using high performance liquid chromatography (HPLC). Results: The personal exposure level of FA was higher than the indoor concentration, and the personal exposure levels of instructors were higher than that of the students. The concentration of FA was also higher in the center of the room than the corners and near the doors. Conclusion: Both the indoor FA concentrations and personal FA exposure levels are higher near the dissecting table than at locations away from it during the gross anatomy laboratory sessions. Thus, the instructors and students are exposed to the higher concentration of FA than the general population.
\end{abstract}

Key words:

Formaldehyde, Formalin, Gross anatomy laboratory, Dissection room, Personal exposure level

\section{INTRODUCTION}

Cadaveric dissection is one of the essential tools for gross anatomy teaching in most of the medical colleges; cadavers are embalmed and preserved in FA for long term use. Vapors of FA emitted during the dissection sessions elevate the indoor FA concentration that results in increased level of exposure for medical students and instructors. The present study was conducted to correlate the personal FA exposure level with that of indoor concentration. The WHO indoor air quality guideline proposed less than $0.08 \mathrm{ppm}$ for indoor concentration of FA [1]. The American Conference of Governmental Industrial Hygienists (ACGIH) has set a ceiling limit for FA at $0.3 \mathrm{ppm}$ [2]. FA is a known irritant to the eyes, nose and throat [3]. The International Agency for Research on Cancer (IARC) and U.S. Environmental Protection Agency (EPA) classified FA as a human carcinogen during high or prolonged exposure [4].

Received: February 01, 2010. Accepted: November 29, 2010.

Address reprint request to M.S. Vohra, Stem Cell Unit, Department of Anatomy College of Medicine, King Saud University, Riyadh - 11461, Saudi Arabia (e-mail: vohra@ksu.edu.sa). 
The participants of gross anatomy laboratory are exposed to a higher concentration of FA than the general population [5-7]. Very few reports are available in the literature on the personal FA exposure levels.

\section{METHODS}

The dissection room at the College of Medicine in King Saud University (Figure 1) was evaluated during the 4 th, 10 th $\& 14$ th weeks. The dimensions of room are $30 \times 15 \times 4 \mathrm{~m}$ and total room volume is $1800 \mathrm{~m}^{3}$. Three doors of the room are leading to different corridors (door 1), main lobby (door 2) demonstrator's offices (door 3) small corridor (Figure 1). All the doors remain closed when not in use. The dissection room is also provided with six permanently closed glass windows along one side of the room. Twenty four ceiling diffusers arranged in four rows are attached to the central air conditioning system and four exhausts provide general ventilation to the laboratory (Figure 1). There is no natural ventilation. Cadavers for dissection are prepared in FA solution. The solution consisted of glycerin, FA 5-7\%, and tap water. While not in use, each cadaver is wrapped in cotton cloth and is enclosed in a vinyl bag equipped with a fastener. During the study, fourteen cadavers were placed over the fixed tables, and each cadaver was allotted to twenty students and an instructor. Air samples were collected from three points, the centre, close to the doors and four corners of the laboratory (Figure 1, CE, D1-D3, CR1-CR4) during the dissecting sessions of 2-3 hours. Two sampling devices were placed at an average height of breathing zone of instructors and students at each spot as well as the personal samples were also taken from instructors and students using the diffusive sampling device (Sigma Aldrich MO, USA), as described previously [8-10]. Ten instructors and 20 students participated in this study during each dissection session. A sampling device was attached to subject's collar for 2 to 3 hours during the dissection class. Analysis of the collected samples were carried out using high performance liquid chromatography (HPLC) with Shimadzu SPD-M10Avp Diode Array Detector.

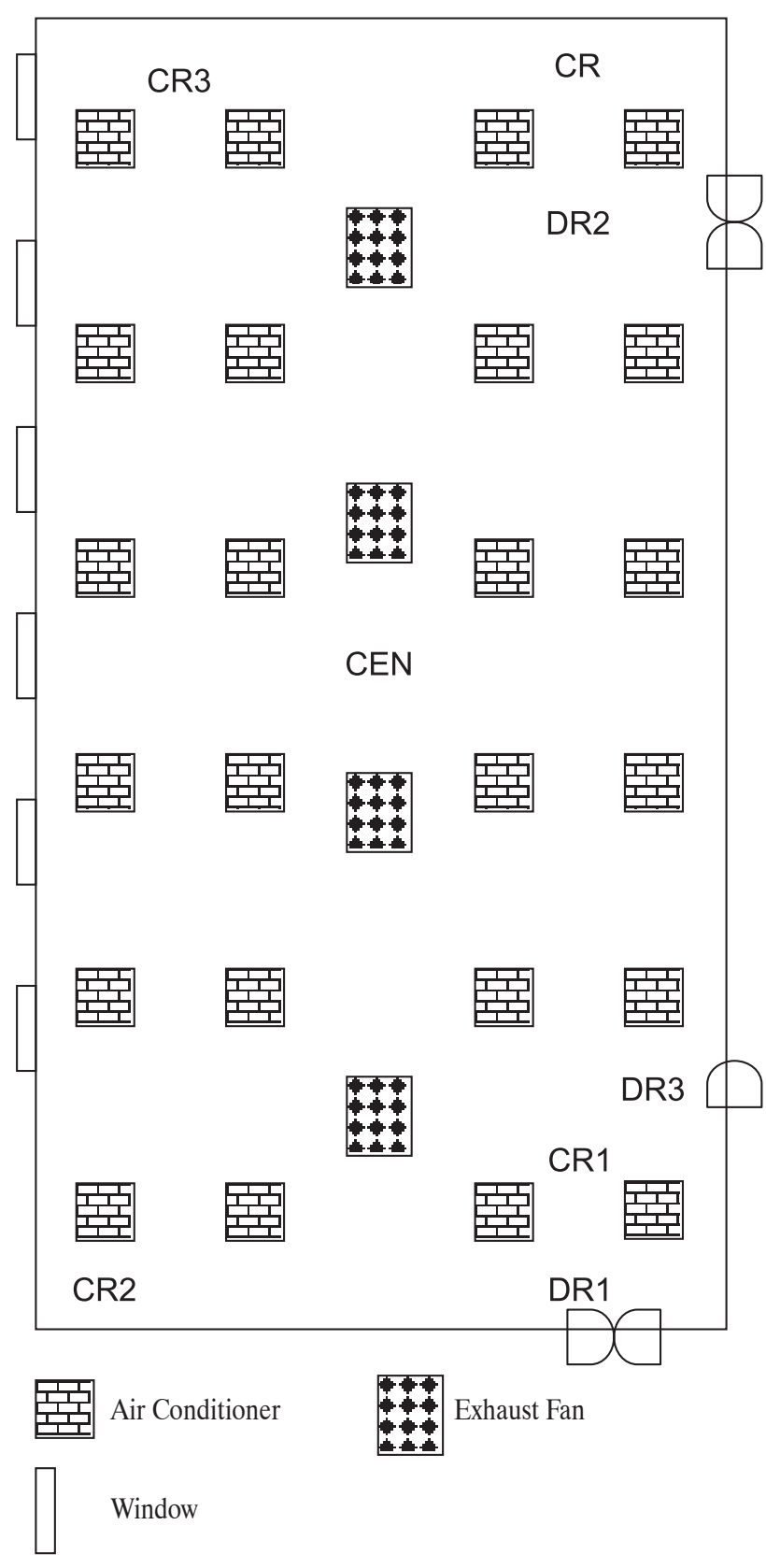

CR1-CR4 - corners; CEN - centre; DR1-DR3 - doors.

Fig. 1. Layout of gross anatomy dissecting room. 


\section{Statistical Analysis}

The statistical significance of group differences among indoor FA concentration, and FA exposure levels of instructors and students were analyzed by one-way ANOVA, and then the significance of differences between each of the two groups were determined by the $t$-test. Differences were considered significant only when the $P$-value was less than 0.05 .

\section{RESULTS}

The average concentration of FA in dissection room was $0.68,0.85$, and $0.73 \mathrm{ppm}$ in the 4th, 10 th and 14 th weeks, respectively. A significant variation in indoor FA concentrations was observed in different areas of the dissection room and also during the dissection

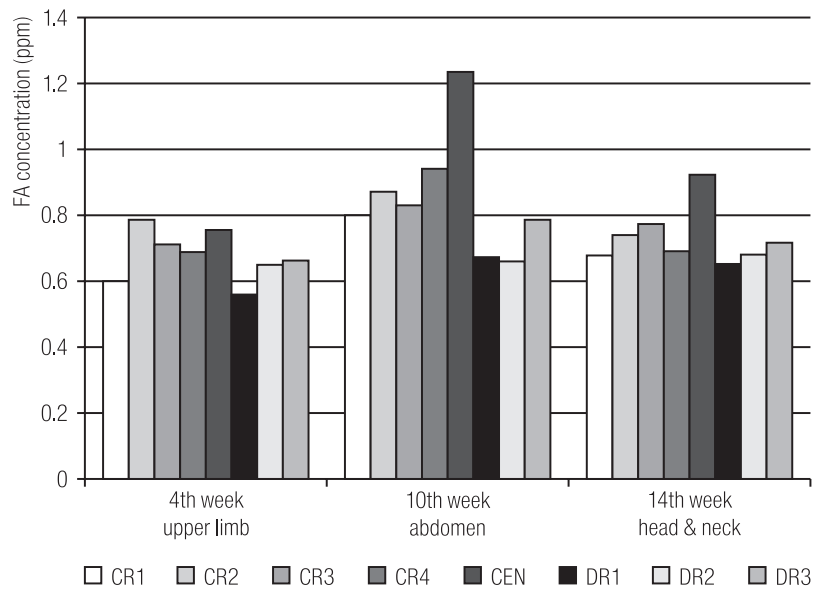

Abbreviations as in Fig. 1.

Each bar represents the mean of two samples.

Fig. 2. Indoor FA concentration at the corners, the centre and the doors of the gross anatomy dissection room.

Table 1. Measurement of formaldehyde concentration and exposure level in the dissection room

\begin{tabular}{lccc}
\hline & \multicolumn{3}{c}{$\begin{array}{c}\text { Average concentrations (min-max) } \\
\text { Sample area }\end{array}$} \\
\cline { 2 - 4 } & $\begin{array}{c}\text { 4th week } \\
\text { upper limb }\end{array}$ & $\begin{array}{c}10 \text { th week } \\
\text { abdomen }\end{array}$ & $\begin{array}{c}1 \text { th week } \\
\text { head \& neck }\end{array}$ \\
\cline { 2 - 4 } CR1 & $0.60(0.57-0.63)$ & $0.80(0.78-0.81)$ & $0.68(0.66-0.70)$ \\
CR2 & $0.79(0.78-0.80)$ & $0.87(0.86-0.88)$ & $0.74(0.76-0.72)$ \\
CR3 & $0.71(0.70-0.72)$ & $0.83(0.77-0.89)$ & $0.77(0.76-0.76)$ \\
CR4 & $0.69(0.67-0.71)$ & $0.94(0.90-0.98)$ & $0.69(0.67-0.69)$ \\
CEN & $0.75(0.72-0.78)$ & $1.23(1.17-1.29)$ & $0.92(0.93-0.92)$ \\
DR1 & $0.56(0.53-0.59)$ & $0.67(0.65-0.69)$ & $0.65(0.65-0.66)$ \\
DR2 & $0.65(0.64-0.66)$ & $0.66(0.64-0.68)$ & $0.68(0.69-0.67)$ \\
DR3 & $0.66(0.63-0.69)$ & $0.79(0.75-0.79)$ & $0.72(0.71-0.73)$ \\
Mean & 0.68 & 0.85 & 0.73 \\
Students & $0.75(0.62-0.89)$ & $1.20(0.98-1.42)$ & $1.10(0.88-1.31)$ \\
Instructors & $1.27(0.82-1.72)$ & $1.44(1.18-1.70)$ & $1.33(0.94-1.72)$ \\
Student (mean \pm SD) & $0.75 \pm 0.08$ & $1.2 \pm 0.14$ & $1.1 \pm 0.17$ \\
Instructor (mean \pm SD) & $1.27 \pm 0.27$ & $1.46 \pm 0.21$ & $1.33 \pm 0.22$ \\
P-Value (Student t-test) & $0.0000^{*}$ & $0.0000^{*}$ & $0.0007^{*}$ \\
Instructor & $1.27 \pm 0.27$ & $1.46 \pm 0.21$ & $1.33 \pm 0.22$ \\
Students & $0.75 \pm 0.08$ & $1.2 \pm 0.14$ & $1.1 \pm 0.17$ \\
Dissection Room & $0.68 \pm 0.08$ & $0.85 \pm 0.18$ & $0.73 \pm 0.09$ \\
P-value (one way ANOVA) & $<0.001$ & $<0.001$ & $<0.001$ \\
\hline
\end{tabular}

Abbreviations as in Figure 1.

$* p<0.05$ statistically significant on the basis of students $t$ - test and $<0.001$ on the basis of one way ANOVA. 
sessions. FA concentration was higher during body cavity or deep dissection (Table 1). In all sessions, FA levels near the dissecting table were higher than in the areas away from it. The average personal exposure level for the students was $0.75,1.20$, and $1.10 \mathrm{ppm}$ and $1.27,1.44$ and 1.33 ppm for instructors during the 4 th, 10th and 14 th week, respectively (Table 1). These levels were relatively higher than the World Health Organization (WHO) guideline [1]. These levels were always higher than the average indoor concentrations throughout the laboratory sessions (Figure 2) and the difference in FA personal exposure levels between instructors and students might reflect both the time spent in a particular area in the dissection room and the region of the cadaver they dissect.

\section{DISCUSSION}

Recently the issue of FA exposure is becoming a matter of concern amongst the participants of cadaveric dissection sessions in the gross anatomy laboratories. To prevent significant sensory irritation in the general population, WHO recommends an air quality guideline value of $0.1 \mathrm{mg} / \mathrm{m}^{3}$ $(0.08 \mathrm{ppm})$ as a 30-minute average for FA [1]. Previous studies have demonstrated the indoor FA levels in gross anatomy laboratory exceeding the limits set by WHO. The National Institute for Occupational Safety and Health (NIOSH) reported significant exposures to FA in a gross anatomy laboratory at a medical school in Colorado [12]. The personal exposure levels with no difference [14] or student's FA exposure level higher than instructors [6] have been reported.

Previously it has been demonstrated that indoor FA concentration and personal exposure levels in gross anatomy laboratories exceed the admissible limits [13]. It has been demonstrated that the average FA concentrations in the gross anatomy laboratory ranged from 0.51$1.46 \mathrm{ppm}$, which was higher than the ACGIH ceiling limit of $0.3 \mathrm{ppm}$ [11]. The indoor FA concentrations in gross anatomy laboratories have been reported previously [1,7,10-11] but only few have described the personal FA exposure levels. The personal exposure levels are more significant for the assessment of health risk than indoor FA concentrations, since it may vary depending on the time spent in dissection room, person's behavior, and the region of the dissected cadavers.

In the previous literature the mean personal FA exposure levels were $1.69 \mathrm{ppm}$ and $1.53 \mathrm{ppm}$ for instructors and students, respectively, while mean area value was $0.50 \mathrm{ppm}$ [9], $1.24 \mathrm{ppm}$ as the mean personal exposure level and $1.65 \mathrm{ppm}$ indoor FA level, for the length of time required for completion of assignments in the gross anatomy laboratory [12]. However, they neither mentioned the difference between personal exposure levels and indoor concentrations, nor between instructors and students. It has also been reported $[8,9,12]$ that the FA levels are variable depending on the region being dissected. Therefore it is important to know the personal exposure levels in each laboratory session.

The present study shows that the personal FA exposure levels of instructors are higher than those of students (Figure 3). This may be because in the gross anatomy laboratory at King Saud University, the cadavers are dissected mainly by the instructors before the actual session starts this might reflect higher exposure level of instructors in this study (Figure 3). The lowest indoor FA concentration was observed at door 1 and 2; this might be due to leakage of the indoor air as the large number of students use these doors to enter and to leave the dissection room during the dissection session. This shows importance of the local ventilation in the dissection rooms as many of the medical schools have their gross anatomy dissection rooms in the basements, which should be discouraged.

The mean indoor FA concentration was lowest during the 4th week when region of the arm was being dissected and it was the highest in the 10th week (Table 1, Figure 2) during the abdominal cavity dissection. In 14th week 


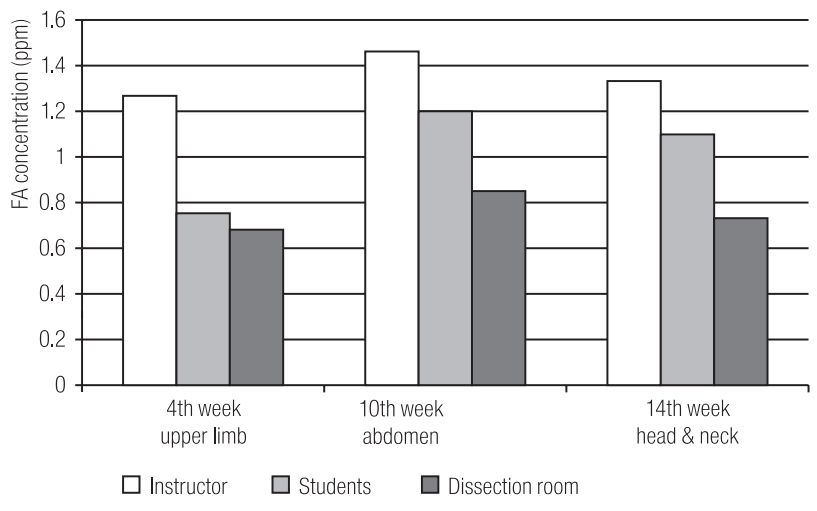

Fig. 3. Mean of the indoor FA concentrations of anatomy dissection room and personal exposure levels for instructors and students.

during the dissection of the deep structures in the neck region, the indoor FA concentration was eventually higher than the 4th week but it was lower than that of 10th week, thus the indoor FA concentration is higher when the body cavity or deeper structures are being dissected (Table 1, Figure 2).

Instructors dissect the cadavers 1-2 hours before the actual time, and then demonstrate to the students, by doing this the instructors spend more time in close vicinity of cadavers than students, and this time difference reflects the difference in personal exposure levels of instructors and students. However, the range of personal exposure levels was much wider than that of area levels, and the maximum personal level was about 1.78-fold higher than the mean area level [12].

Present study suggests that the personal exposure level for a person close to the dissecting table is always greater than the average indoor FA concentration, because vaporization from cadavers and their containers is the main pathway of FA exposure in the gross anatomy laboratories. It is suggested that personal exposure level of a person is directly proportional to the time spent in an area of relatively higher FA concentration.

However, it is not possible to measure the FA exposure level of all the subjects. but its concentration can be reduced. This can be achieved by providing the local ventilation system or/and the indoor air may immediately be exhausted before it spreads in the laboratory. It is suggested that further studies are needed to protect the medical students and the teaching staff from harmful effect of FA.

\section{CONCLUSIONS}

The present study has revealed that the indoor FA concentration is higher near the dissecting tables compared to the other areas of the dissection room; therefore, a person close to the dissecting table may have a higher degree of FA exposure than the one away from it. Moreover, the personal FA exposure levels are higher during the dissection of body cavity and deeper structures in comparison with other regions of the body, suggesting that the instructors and students are exposed to higher concentration of FA than the general population.

\section{ACKNOWLEDGEMENT}

The author is thankful to Dr. Muhammad Mujahid Khan for his enormous support and critical review of the manuscript and to Mr. Muneer Shareef (MSc.) for the statistical analysis of data. $\mathrm{He}$ is also indebted to Professor Dr. Sultan Ayub Meo for his technical assistance. The author extends deep appreciation to Dr. Abdullah Aldahamash, Founder of Stem Cell Unit and Chairman, Anatomy Department, King Saud University, for his immense support to this project.

\section{REFERENCE}

1. WHO. Air Quantity Guidelines for Europe. 2nd ed. Chapter 5.8. Formaldehyde. Copenhagen: WHO; 2000. p. 87-91 [cited 2010 Feb 1]. Available from URL: http://www.euro. who.int/_data/assets/pdf_file/0005/74732/E71922.pdf.

2. American Conference of Governmental Industrial Hygienists (ACGIH). Notice of intended change - formaldehyde. Appl Occup Environ Hyg 1992;7:852-74. 
3. Paustenbach D, Alarie Y, Kulle T, Schachter N, Smith R, Swenberg J, et al. A recommended occupational exposure limit for formaldehyde based on irritation. J Toxicol Environ Health 1997;50(3):217-63.

4. International Agency for Research on Cancer (IARC). IARC Monograph on the Evaluation of Carcinogenic risks to Humans. Formaldehyde, 2-Butoxyethanol and 1-tert-Butoxypropan-2-ol. Lyon: IARC; 2006.

5. Skisak CM. Formaldehyde vapor exposures in anatomy laboratories. Am Ind Hyg Assoc J 1983;44:948-50.

6. Ohmichi K, Komiyama M, Matsuno Y, Takanashi Y, Miyamoto H, Kadota T, et al. Formaldehyde exposure in a gross anatomy laboratory - personal exposure level is higher than indoor concentration. Environ Sci Pollut Res Int 2006;13(2):120-4.

7. Tanaka K, Nishiyama K, Yaginuma H, Sasaki A, Maeda T, Kaneko SY, et al. Formaldehyde exposure levels and exposure control measures during an anatomy dissecting course. Kaibogaku Zasshi 2003;78(2):43-51.
8. Uchiyama S, Hasegawa S. A reactive and sensitive diffusion sampler for the determination of aldehydes and ketones in ambient air. Atomosph Environ 1999;33(13):1999-2005.

9. EPA. Determination of Formaldehyde in Ambient Air Using Adsorbent Cartridge Followed by High-Performance Liquid Chromatography (HPLC), Method TO-11A. EPA/625/R96/010b; Washington, DC: Center for Environmental Research Information Office of Research and Development, 1999 [cited 2010 Feb 1]. Available from URL: http:// www.epa.gov/ttn/amtic/files/ambient/airtox/to-11ar.pdf.

10. NIOSH. Formaldehyde: method 2016. In: NIOSH. Manual of analytical method. 4th ed. [cited 2005 May 15]. Available from URL: http://www.cdc.gov/niosh/nmam/pdfs/2016.pdf.

11. ACGIH. TLVs and BEIs. Threshold limit values for chemical substances and physical agents and biological exposure indices. Cincinnati, OH: ACGIH; 2002.

12. Formaldehyde exposures in a gross anatomy laboratory. Morb Mortal Wkly Rep 1983;31(52):698-700.

13. Perkins JL, Kimbrough JD. Formaldehyde exposure in a gross anatomy laboratory. J Occup Med 1985;27(11):813-5.

This work is available in Open Access model and licensed under a Creative Commons Attribution-NonCommercial 3.0 Poland License - http://creativecommons.org/ licenses/by-nc/3.0/pl/deed.en. 